\title{
Effectiveness of apraclonidine $1 \%$ in preventing intraocular pressure rise following macular hole surgery
}

\author{
Andrea Sciscio, Anthony G Casswell
}

\begin{abstract}
Aim-To determine the efficacy of apraclonidine hydrochloride $1 \%$ in preventing intraocular pressure (IOP) spikes following idiopathic macular hole (IMH) surgery with platelet adjunct and intraocular gas tamponade.
\end{abstract}

Methods-This is a prospective, double masked, randomised study to compare apraclonidine hydrochloride $1 \%$, an $\alpha_{2}$ agonist, with a placebo in the prevention of IOP rises following macular hole surgery. Each patient was randomly selected to receive either the study drug or the placebo; one drop was instilled in the conjunctival sac 2 hours preoperatively and on completion of the procedure. IOP was measured at baseline and at 1, 3, 6, 24, 48 hours, and 2 weeks postoperatively. Blood pressure and heart rate were also recorded at baseline and at 3 and 24 hours postoperatively. Macular hole repair surgery was performed as standardised in the unit with a vitrectomy, platelet concentrate, and complete fill of the vitreous cavity with perfluoropropane gas $\left(\mathrm{C}_{3} \mathrm{~F}_{8}\right)$ at a concentration of $16 \%$.

Results-25 patients (26 eyes) were enrolled. 12 eyes received apraclonidine hydrochloride $1 \%$ (mean age 70.7 ; range 62-78 years) and 14 eyes received the placebo (mean age 70.0 ; range $57-81$ years). At baseline evaluation the mean IOP was $15.6 \mathrm{~mm} \mathrm{Hg}$ for the study group and $14.3 \mathrm{~mm} \mathrm{Hg}$ for the placebo group. The mean postoperative IOP at 1 hour, 3 hours, 6 hours, and 24 hours was 10.6, 9.6, 8.2 , and $14.0 \mathrm{~mm} \mathrm{Hg}$ in the apraclonidine group. In the control group at the same time intervals the mean IOP was 23.4 , $17.5,19.2$, and $24.7 \mathrm{~mm}$ Hg. These readings were statistically significant different: 1 hour ( $p=0.0001)$; 3 hours $(p=0.0015) ; 6$ hours $(p<0.0001)$; and 24 hours $(p=0.019)$, the readings at 48 hours and 2 weeks were not statistically significant different $(p=0.15$ and $p=0.59)$. Only one of the patients in the study group had an IOP above $25 \mathrm{~mm} \mathrm{Hg}$ at any time. In the control group an IOP above $25 \mathrm{~mm} \mathrm{Hg}$ was found in seven patients $(50 \%)$ at the 1 hour postoperative measurement. At 2 weeks the IOP was recorded below $25 \mathrm{~mm}$ $\mathrm{Hg}$ in all patients. No statistically significantly difference was noted between the two groups regarding the systolic or diastolic blood pressure values and the heart rate records. No local or systemic adverse reactions were observed. Conclusions-Apraclonidine hydrochloride $1 \%$ appears to be an efficacious and safe drug in the prophylaxis of early postoperative IOP elevations in patients undergoing macular hole surgery.

(Br f Ophthalmol 2001;85:164-168)

Macular hole surgery has become increasingly successful since it was first described. ${ }^{1}$ Protocols are varied, depending on the use of different types and concentrations of tamponading agents or the use of adjuvant substances in promoting healing (recombinant or bovine transforming growth factor $\beta_{2}\left(\mathrm{TGF} \beta_{2}\right)$, autologous platelet concentrate, or tissue glue)..$^{2-4}$

Specific complications related to this procedure have been reported, including visual field defects and sustained intraocular pressure (IOP) elevation. ${ }^{5-7}$ Raised IOP is even more pronounced when adjuvants are used. ${ }^{6}$ The incidence of raised IOP (more than $30 \mathrm{~mm}$ $\mathrm{Hg}$ ) varies between $15 \%$ and $22 \%$ of patients in the first 24 postoperative hours. ${ }^{6}$ In a significant number of patients this transient rise can last up to 2 weeks. ${ }^{67}$

The complication of raised postoperative IOP is potentially preventable with prophylactic pharmacological treatment. Apraclonidine hydrochloride $1 \%$ is successful in the prevention of IOP rises following YAG capsulotomy, argon laser trabeculoplasty, cycloplegia, and cataract extraction..$^{8-11}$

We conducted a prospective, randomised, double masked study to determine the efficacy of apraclonidine hydrochloride $1 \%$ to control these IOP spikes following surgery for macular hole repair.

Patients and methods

The study was designed accordingly to the Declaration of Helsinki standards. Local ethics committee and the Medicine Control Agency approval for the study was obtained. Exclusion criteria were: history of glaucoma, ocular hypertension, previous ocular surgery, or ocular laser treatment, active ocular inflammation, uniocular patients, patients affected by cardiovascular, pulmonary, or renal disease with the exception of medically controlled systemic hypertension. Patients were also excluded if they were taking systemic sympathomimetics, monoamine oxidase inhibitors, or tricyclic antidepressants, and if they were known to have had hypersensitivity reactions to clonidine derivatives. 
Twenty five consecutive patients affected by idiopathic macular hole (IMH) meeting these entry criteria were enrolled in the study. Patients were then counselled preoperatively on the purpose of the study and written informed consent was obtained to participate.

All eligible patients underwent full preoperative ophthalmological examination, including best corrected visual acuity for near and distance, slit lamp biomicroscopy of the anterior segment, and dilated funduscopy, and also electrocardiogram and blood glucose analysis. Baseline evaluation of the main outcome measurement, IOP, was recorded with a Goldmann applanation tonometer. Blood pressure and heart rate were also recorded. Patients were then randomly assigned to the study or placebo group. The randomisation code was obtained from computer generated random number table; this assigned a random number to each identical Minims for each sequential patient before commencement of the study. All Minims sachets were identical apart from the identification number to ensure absolute masking of the study at the time of instilling drops and also when the IOP was measured. One drop (approximately $30 \mu \mathrm{l}$ ) of the study drug (apraclonidine hydrochloride $1 \%$ ) or placebo (sodium chloride $0.9 \%$ ) was instilled in the conjunctival sac 2 hours preoperatively.

Pupil dilatation was started 1 hour before surgery with one drop each of phenylephrine $10 \%$ and cyclopentolate $1 \%$. This was repeated after 15 and 30 minutes. Patients received also one drop of diclofenac $4 \%$ at the same timings.

Local anaesthesia was obtained by a peribulbar block technique. Between 7 and $10 \mathrm{ml}$ of a mixture of $50 \%$ of bupivacaine $0.5 \%$ and lignocaine $2 \%$, with the addition of 300 IU of Hylase, were injected inferotemporally $(70 \%)$ and medially $(30 \%)$.

A single experienced vitreoretinal surgeon (AGC) carried out the surgical procedure as follows: three port pars plana vitrectomy with self sealing sclerotomies, removal of the posterior cortical hyaloid, and careful epiretinal membrane dissection if judged clinically significant. Air-fluid exchange was repeated after 5 minutes, and $0.1 \mathrm{ml}$ of autologous platelet concentrate was used as adjuvant. ${ }^{12}$ Perfluoropropane gas $\left(\mathrm{C}_{3} \mathrm{~F}_{8}\right)$ at a concentration of $16 \%$ was exchanged to achieve a complete fill of the vitreous cavity.

On completion of surgery patients received a subconjunctival injection of cefuroxime 125 $\mathrm{mg}$ and betamethasone $2 \mathrm{mg}$ diluted in $2 \mathrm{ml}$ of sterile water. One drop of the study drug or the placebo, depending on randomisation, was instilled in the conjunctival sac. The eye was then covered with Jelonet, a double pad, and a shield. No other systemic or topical IOP lowering agents other than apraclonidine hydrochloride $1 \%$, where applicable, were administered at the time of surgery.

Strict supine position was maintained for the first 24 hours. At 1 hour, 3 hours, and 6 hours postoperatively the IOP was measured with a calibrated Perkins applanation tonometer by the same clinician (AS), who also recorded all subsequent IOPs at 24 and 48 hours and at 2 weeks. To ensure reliability between the Perkins and Goldmann tonometer these were cross checked at the beginning of the study. At 24 hours patients were examined on the slit lamp and the IOP was measured with a Goldmann tonometer. Blood pressure and heart rate were taken at 3 hours and 24 hours postoperatively by a trained nurse.

Patients were then commenced on dexamethasone $0.1 \%$ and neomycin $0.5 \%$ ointment twice a day and instructed to posture prone or maintain a face down position for the following 2 weeks. The subsequent IOP recordings at 48 hours and 2 weeks were obtained again with a Goldmann tonometer. All patients were examined postoperatively to assess the gas bubble size as part of a full ophthalmic examination.

Based on a power of $90 \%$ and an $\alpha$ of 0.05 , and assuming an effectiveness of $25 \%$ for the placebo $\left(\pi_{1}\right)$ and of $80 \%$ for the study drug $\left(\pi_{2}\right)$, the calculated sample size was of 12 eyes in each group. Considering the eventuality of dropouts for various reasons we recruited a slightly larger number of patients. Only at the end was the code broken and the data collected were analysed. A statistician performed the statistical analysis with the software package STATA. We used the two sample Student's $t$ test with equal variance to calculated significance and also determined the $95 \%$ confidence intervals for each postoperative measurement.

\section{Results}

After randomisation, 12 eyes were assigned to the study group and 14 eyes to the placebo group; all patients completed the trial. The demographic data of the two groups are presented in Table 1 . In the study group 11 eyes were diagnosed with a stage III IMH and one with stage IV. In the placebo group 10 eyes were affected by a stage III and four eyes by a stage II IMH. Mean symptoms duration was 6 (SD 3.05) months in the study group and 5.35 (3.70) months in the placebo group.

All surgical procedures were uneventful and, in particular, none required lens extraction or cryotherapy for intraoperative complications.

INTRAOCULAR PRESSURE

The mean preoperative IOP was 15.6 (2.6) $\mathrm{mm} \mathrm{Hg}$ in the study group and $14.3(2.0) \mathrm{mm}$ $\mathrm{Hg}$ in the control group.

The mean IOP at 1 hour was $10.6(7.0) \mathrm{mm}$ $\mathrm{Hg}$ in the apraclonidine group and 23.4 (6.4) $\mathrm{mm} \mathrm{Hg}$ in the placebo group with a difference of $12.7 \mathrm{~mm} \mathrm{Hg}$ (95\% confidence intervals 18.2 to $7.2, p=0.0001)$. At 3 hours means were 9.6 (4.2) $\mathrm{mm} \mathrm{Hg}$ and 17.5 (6.5) $\mathrm{mm} \mathrm{Hg}$ in the apraclonidine and the study group respectively, with a difference of $7.9 \mathrm{~mm} \mathrm{Hg}(95 \%$ confidence intervals 12.4 to $3.3, \mathrm{p}=0.0015)$. At 6 hours the respective values as above were 8.2 (3.7) $\mathrm{mm} \mathrm{Hg}$ and 19.2 (6.8) $\mathrm{mm} \mathrm{Hg}$, with a difference of $11.0 \mathrm{~mm} \mathrm{Hg}$ (95\% confidence intervals 15.6 to $6.4, \mathrm{p}<0.0001)$. For the 24 hours measurement, again the respective values were 14.0 (5.7) $\mathrm{mm} \mathrm{Hg}$ and 24.7 (13.8) $\mathrm{mm} \mathrm{Hg}$, with a difference of $10.7 \mathrm{~mm} \mathrm{Hg}$ 
Table 1 Demographic data $(n=25)$

\begin{tabular}{lll}
\hline & Apraclonidine group & Placebo group \\
\hline Number of eyes & 12 & 14 \\
Mean age (years)/range & $70.7 / 60-78$ & $70.0 / 57-81$ \\
Male:female ratio & 0.5 & 0.16 \\
Male & 4 & 2 \\
Female & 8 & 12 \\
Race & All white & All white \\
\hline
\end{tabular}

Table 2 Values of eyes with more than $30 \mathrm{~mm} \mathrm{Hg}$ of intraocular pressure. The bold figures indicate treatment with a topical $\beta$ blocker and oral acetazolamide; this regimen was continued until the IOP returned to a level below $21 \mathrm{~mm} \mathrm{Hg}$. Four patients (28\%) in the placebo group had an IOP above $30 \mathrm{~mm} \mathrm{Hg}$ at 24 hours and three patients (21\%) at 48 hours

\begin{tabular}{llllllll}
\hline $\begin{array}{l}\text { Patient No } \\
\text { Apraclonidine group: }\end{array}$ & Preop & 1 hour & 3 hours & 6 hours & 24 hours & 48 hours & 2 weeks \\
\hline $\begin{array}{l}\text { Alacebo group: } \\
17\end{array}$ & 5 & 10 & 10 & 17 & 34 & $\mathbf{1 4}$ \\
6 & 18 & 21 & 14 & 16 & $\mathbf{6 0}$ & $\mathbf{3 5}$ & $\mathbf{1 4}$ \\
8 & 15 & $\mathbf{3 2}$ & $\mathbf{2 5}$ & $\mathbf{1 8}$ & $\mathbf{3 3}$ & $\mathbf{7}$ & $\mathbf{N R}$ \\
9 & 11 & 25 & 12 & $\mathbf{3 6}$ & $\mathbf{3 9}$ & $\mathbf{3 2}$ & $\mathbf{2 0}$ \\
11 & 14 & 28 & 29 & 28 & $\mathbf{3 4}$ & $\mathbf{3 2}$ & $\mathbf{2 2}$
\end{tabular}

$\mathrm{NR}=$ not recorded.

(95\% confidence intervals 19.5 to 1.8 , $\mathrm{p}=0.019)$.

The mean IOP measurements at 48 hours were 17.2 (7.0) $\mathrm{mm} \mathrm{Hg}$ and 22.5 (9.5) $\mathrm{mm} \mathrm{Hg}$ in the apraclonidine group in the control group, respectively, the difference was 5.25 $\mathrm{mm} \mathrm{Hg}$ (95\% confidence intervals 1.6 to 2.1, $\mathrm{p}=0.154)$; at 2 weeks the respective values were 16.5 (4.2) $\mathrm{mm} \mathrm{Hg}$, and 17.4 (3.3), difference of $0.9 \mathrm{~mm} \mathrm{Hg}$ (95\% confidence intervals 4.3 to 2.5, $\mathrm{p}=0.590)$.

In the apraclonidine group only one eye (8\%) had an IOP above $25 \mathrm{~mm} \mathrm{Hg}$, this was at the 48 hour reading. In the placebo group an IOP above $25 \mathrm{~mm} \mathrm{Hg}$ was found in seven eyes (50\%) at 1 hour, two eyes $(14 \%)$ at 3 hours, three eyes $(21 \%)$ at 6 hours, six eyes (43\%) at 24 hours, and four eyes (28\%) at 48 hours postoperatively. At 2 weeks the IOP was recorded below $25 \mathrm{~mm}$ $\mathrm{Hg}$ in all eyes of the two groups.

Four patients in the placebo group and one in the apraclonidine group had an IOP above $30 \mathrm{~mm} \mathrm{Hg}$ (Table 2) and required additional treatment with topical $\beta$ blockers and oral acetazolamide.

All patients were examined postoperatively to assess the gas bubble size. The size varied between $70 \%$ and $90 \%$ at 24 hours; no patient had a complete fill of gas.

CARDIOVASCULAR VARIABLES

At all time intervals there was no statistically significant difference between the two groups in the systolic or diastolic blood pressure, systolic at 3 hours $p=0.869$ and at 24 hours $\mathrm{p}=0.770$, diastolic at 3 hours $\mathrm{p}=0.171$ and at 24 hours $p=0.386$. Similarly the heart rate showed no difference, 3 hours $p=0.951$ and at 24 hours $p=0.330$. No systemic or local reactions were observed in patients receiving apraclonidine.

\section{Discussion}

Postoperative elevation of intraocular pressure is a well recognised complication of vitrectomy procedures. ${ }^{7}$ This randomised controlled study of patients undergoing vitrectomy for macular hole surgery involving prolonged intraocular gas tamponade and platelet adjuvant, has shown that apraclonidine has a significant effect on reducing postoperative pressure elevation during the first week postoperatively. We have also demonstrated that a relatively high incidence of elevated IOP occurs in the immediate postoperative period, between 24 and 48 hours. However, at 2 weeks none of the patients had an IOP above $30 \mathrm{~mm} \mathrm{Hg}$. In the control group a significant IOP spike (above 30 $\mathrm{mm} \mathrm{Hg}$ ) occurred in four eyes at 24 hours and in three eyes at 48 hours, whereas in the apraclonidine group in only one eye at 48 hours.

Han et al found "postvitrectomy IOP elevations" of $30 \mathrm{~mm} \mathrm{Hg}$ or more in 79 eyes (35.6\%) in a series of 222 patients. ${ }^{13}$ The diagnostic range was rather wide including rhegmatogenous retinal detachment, retinal detachment with proliferative retinopathy, diabetic vitreous haemorrhage or tractional retinal detachment, etc. Only one patient was operated on for an impending macular hole. Analysis of risk factors led to the conclusion that there was a positive correlation between IOP elevation and scleral buckling in particular, as well as lensectomy, fibrin formation, and scatter endophotocoagulation. In our case series none of these risk factors was present and other possible mechanisms for postoperative IOP spikes have to be considered.

In the current study, four eyes $(28 \%)$ in the placebo group were recorded with an IOP above $30 \mathrm{~mm} \mathrm{Hg}$ at 24 hours. Our results are slightly higher of those reported by Chen in his retrospective review, who found a $15 \%$ incidence (six out of 40 patients) of raised IOP (>30 mm Hg) at 24 hours. $^{7}$ However, in his surgical procedure no adjuvants were used to promote healing of the macular hole.

Thompson, in his elegant study, has demonstrated how the type of adjuvant used can have a determinant effect on postoperative IOP elevations. ${ }^{6}$ In one arm of the study, all eyes received bovine $\mathrm{TGF} \beta_{2}$ and were studied for the effect of different concentrations of perfluoropropane or air alone on the IOP. No statistically significant difference in the risk of developing an increased IOP was demonstrated between the various groups. However, a relatively significant IOP increase was found at 2 weeks mainly, ranging from $6.7 \%$ to $26.7 \%$, but none at 48 hours. Conversely, in his other study group recombinant $\mathrm{TGF} \beta_{2}$ was compared with a placebo, all eyes had a full fill with $16 \%$ perfluoropropane. It was found that the group treated with TGF $\beta_{2}$ had a significantly increased IOP at 2 weeks, eight of 28 eyes $(28.5 \%)$ measured an IOP greater than $30 \mathrm{~mm} \mathrm{Hg}$.

These results are somewhat different from ours, in that we found that an increased IOP (>30 $\mathrm{mm} \mathrm{Hg}$ ) in our control group mostly occurred between 24 and 48 hours, four eyes $(28 \%)$ and three eyes $(21 \%)$ respectively. Whereas at 2 weeks none of the eyes recorded an IOP above $25 \mathrm{~mm} \mathrm{Hg}$. It is possible to speculate, considering that we have been using the same type and concentration of tamponading agent as their second arm of the study group, 
that the difference could be related to the adjuvant used.

There are several mechanisms that could explain IOP spikes following macular hole surgery. In our view the most plausible reasons, which are strictly related to this particular type of vitreoretinal surgery, are the presence of intraocular gas, an inflammatory reaction caused by the surgery and the adjuvant (platelets aggregate). These can affect both the ciliary body and the trabecular meshwork function. Another interesting mechanism proposed by Massicotte and Shuman is the obstruction of aqueous outflow by the residual anterior hyaloid. ${ }^{14}$ This could theoretically explain the transient IOP rise in our patients since they were all phakic and none required intraoperative lens extraction. However, we did not notice a shallow anterior chamber in any of our patients. We could speculate that in our case series the IOP was not sufficiently high to make this process irreversible as occurred in Massicotte's patients.

There is clear evidence that apraclonidine hydrochloride $1 \%$ is the drug of choice in the management of short term IOP spikes. ${ }^{15}$ Clinical studies have demonstrated the efficacy of apraclonidine hydrochloride $1 \%$ in reducing the aqueous flow rate up to $35-45 \%$ at 3 hours, and also to increase the trabecular outflow facility. ${ }^{16-18}$ This effect is more pronounced when apraclonidine acts on an uninflamed ciliary body.

With this concept in mind it appears logical to pretreat eyes with an agent such as apraclonidine hydrochloride $1 \%$ to allow maximum effect on the ciliary body before the iatrogenic inflammatory reaction is induced. Apraclonidine hydrochloride $1 \%$, unlike clonidine, does not cross the blood-brain barrier, and has been proved to be relatively safe and effective in avoiding complications such as systemic hypotension and bradycardia. ${ }^{14}$ 19-21

The question whether a short spike of the IOP might have a harmful effect on the ocular tissues, and specifically on the optic nerve head axons might be debatable. It is known from experimental models that an elevated IOP compromises the optic nerve head blood flow, which in turn could affect axonal transport. This vascular theory of axonal damage is probably less important in this mechanism compared to the mechanical one. ${ }^{22}$ Anderson and Hendrickson first demonstrated the impairment of the rapid component of the orthogonal axonal transport in owl monkey eyes during transient IOP elevations as short as $6-8$ hours. Discrete accumulations of the radioactive isotope leucine, injected intravitreally, were observed in the lamina cribrosa and also as far as in the lateral geniculate nucleus. ${ }^{23}$

Minckler likewise found accumulations of granular material in the monkey optic nerve head after only 4 hours following an IOP elevation between 30 and $50 \mathrm{~mm} \mathrm{Hg}$. It is presumed that these granular accumulations are an expression of axonal blockage, and are first observed in the posterior lamina cribrosa when the IOP is kept at $30 \mathrm{~mm} \mathrm{Hg.}{ }^{24}$ The same author proved that the orthogonal axonal transport is equally affected by modest elevations of the IOP, at levels of $25 \mathrm{~mm} \mathrm{Hg}$, even if the partial arterial oxygen tension was kept at levels of $100 \mathrm{~mm} \mathrm{Hg}$. ${ }^{25}$

It is also true that it remains to be verified at what time point such processes become irreversible. Quigley and Anderson showed that it is possible to reverse the axonal blockage if the IOP returns to normal levels within 4 hours. ${ }^{26}$

With this evidence it reasonable to argue that it would be advantageous to maintain an IOP below $30 \mathrm{~mm} \mathrm{Hg}$ to avoid axonal damage at the optic nerve head.

In conclusion, our results demonstrate that apraclonidine hydrochloride $1 \%$ is effective in controlling IOP spikes in the immediate postoperative period. This drug is demonstrated to be safe in the short term and we would thus recommend the use of prophylactic apraclonidine hydrochloride $1 \%$ for patients undergoing macular hole surgery with adjuvants to prevent IOP elevations.

Presented at the Association for Research in Vision and Ophthalmology meeting on the 13 May 1998.

The authors have no financial interest in any of the products mentioned.

1 Kelly NE, Wendel RT. Vitreous surgery for idiopathic macular holes. Results of a pilot study. Arch Ophthalmol 1991;109:654-9.

2 Smiddy WE, Glaser BM, Thompson JT, et al. Transforming growth factor-beta2 significantly enhances the ability to flatten the rim of subretinal macular holes. Preliminary results of a multicentre prospective randomised study. Retina 1993;13:296-301.

3 Korobelnik JF, Hannouche D, Belayachi N, et al. Autologous platelet concentrate as an adjunct in macular hole healing. Ophthalmology 1996;103:590-4.

4 Tilanus MA, Deutman AF. Full-thickness macular holes treated with vitrectomy and tissue glue. Int Ophthalmol 1994-5;18:355-8.

5 Pendergast SD, Brooks W, McCuen II. Visual field loss after macular hole surgery. Ophthalmology 1996;103:1069-77.

6 Thompson JT, Sjaarda RN, Glaser BM, et al. Increased intraocular pressure after macular hole surgery. Am $\mathcal{F} O p h-$ thalmol 1996;121:615-22.

7 Chen CJ. Glaucoma after macular hole surgery. Ophthalmology 1998;105:94-100.

8 Pollack IP, Brown RH, Crandall AS, et al. Prevention of the rise in intraocular pressure following neodymium-YAG posterior capsulotomy using topical $1 \%$ apraclonidine. posterior capsulotomy using topict

9 Robin AL, Pollack IP, House B, et al. Effects of ALO 2145 on intraocular pressure following argon laser trabeculoon intraocular pressure following argon

10 Hill R, Minckler DS, Lee M, et al. Apraclonidine prophylaxis for postcycloplegic intraocular pressure spikes. Ophthalmology 1991:98:1083-6.

11 Wiles S B, MacKenzie D, Ide CH. Control of intraocular pressure with apraclonidine hydrochloride after cataract extraction. Am $\mathcal{f}$ Ophthalmol 1991;111:184-8.

12 Gaudric A, Massin P, Paques M, et al. Autologous platelet concerntrate for the treatment of full-thickness macular holes. Graefes Arch Clin Exp Ophthalmol 1995;233:549-54.

13 Han DP, Lewis H, Lambrou Jr, et al. Mechanism of intraocular pressure elevation after pars plane vitrectomy. Ophthalmology 1989;96:1357-62.

14 Massicotte EC, Shuman JS. A malignant glaucoma-like syndrome following pars plana vitrectomy. Ophthalmology 1999;106:1375-9.

15 Abrams DA, Robin AL, Crandall AS, et al. A limited comparison of apraclonidine's dose response in subjects with normal or increased intraocular pressure. $\mathrm{Am} 7$ with normal or increased

16 Mori M, Araie M. Effect of apraclonidine on blood-aqueous barrier permeability to plasma protein in man. Exp Eye Res 1992;54:555-9

17 Gharagozloo NZ, Relf SJ, Brubaker R. Aqueous flow is reduced by alpha-adrenergic agonist, apraclonidine hydrochloride (ALO 2145). Ophthalmology 1988;95:1217-20.

18 Toris CB, Tafoya BE, Camras CB, et al. Effects of apraclonidine on aqueous humour dynamics in human eyes. Ophthalmology 1995;102:456-61.

19 Abrams DA, Robin AL, Pollack IP, et al. The safety and efficacy of topical 1\% ALO 2145 (p-aminoclonidine hydrochloride) in normal volunteers. Arch Ophthalmol 1987;105: 1205-7.

20 Coleman AL, Robin AL, Pollack IP, et al. Cardiovascular and intraocular pressure effects and plasma concentrations of apraclonidine. Arch Ophthalmol 1990;108:1264-7.

21 Yuksel N, Guler C, Caglar Y, et al. Apraclonidine and clonidine: a comparison of efficacy and side effects in normal and ocular hypertensive volunteers. Int Ophthalmol 1992;16:337-342. 
22 Anderson DR, Davis EB. Sensitivities of ocular tissues to acute pressure-induced ischemia. Arch Ophthalmol 1975,

23 Anderson DR, Hendrickson A. Effect of intraocular pressure on rapid axoplasmic transport in monkey optic nerve. Invest Ophthalmol 1974;13:771-83.

24 Minckler DS. Correlations between anatomic features and axonal transport in primate optic nerve head. Trans $A m$ Ophthalmol Soc 1986;84:429-52.
25 Minckler DS, Bunt AH, Johanson GW. Orthograde and retrograde axoplasmic transport during acute ocular hypertension in the monkey. Invest Ophthalmol Vis Sci 1977;16: 426-41.

26 Quigley H, Anderson DR. The dynamics and location of axonal transport blockade by acute intraocular pressure elevation in primate optic nerve. Invest Ophthalmol 1976;15:606-16. 